\title{
CONSIDERAÇÕES ACERCA DO ATUAL CONTEXTO SÓCIOECONÔMICO E EDUCACIONAL DO BRASIL E SUA REPERCUSSÃO NO PENSAMENTO DE CONSERVAÇÃO AMBIENTAL
}

\author{
Considerations about current context \\ social-economic and educational of the Brazil and \\ its repercussion in the thought of \\ environmental conservation
}

Isonel Sandino MENEGUZZO1

\begin{abstract}
RESUMO
Este texto apresenta uma breve discussão a respeito dos problemas socioeconômicos e educacionais do Brasil, fundamentado numa visão econômica. Discute-se o papel do modo de produção capitalista, a questão das elites, bem como o atual contexto da globalização em que a nação brasileira está inserida, relacionando-os aos problemas socioeconômicos e educacionais do país e ao pensamento de conservação ambiental. A subordinação à economia internacional impelida em diversos momentos da história do Brasil por interesses relacionados às classes nacionais e internacionais dominantes é certamente uma das responsáveis pelos problemas de caráter socioeconômico e, conseqüentemente, ambientais que são vistos atualmente. Os preceitos éticos devem estar presentes na esfera política, econômica, educacional e ambiental, pois sem estes, de pouco valem os esforços realizados no que se refere à conservação ambiental. A visão antropocêntrica deveria ser substituída por uma visão biocêntrica, fundamentada em aspectos ecológicos, que possuem vital importância para a manutenção do equilíbrio ambiental e, conseqüentemente, base para a sustentação da vida com padrões mínimos de qualidade para os seres humanos.
\end{abstract}

Palavras-chave:

Brasil; socioeconomia; questão ambiental.

\begin{abstract}
This paper presents a brief discussion regarding the socialeconomic and education problems of Brazil, basead in an economic vision. The article discuses the paper of the capitalism production, the question of the elites is argued, as well as the current context of the globalization that the brazilian nation is inserted related them it the social-economic and educational problems of the country and to the thought environment, conservation. The economic subordination has impelled international economy at diverse moments of the history of Brazil for interests related to dominancy is certainly one of the responsibity ones for the problems of social-economic character and, consequently environmental who are sun currently. The ethical rules should be parth of the sphere politic, economic, educational and environmental the refore without these, little the efforts carried thourgh as for environmental conservation are valid. The anthropocentric vision would be substituted by a biocentric vision, based upond ecological aspects which possess vital importance for the maintenance of environmental balance and, consequently, as base for the sustentation of the life with minimum standards of quality for human beings.
\end{abstract}

\section{Key words:}

Brazil; social-economy; environmental question.

1 Especialista em Análise Ambiental (UFPR), mestre em Ciência do Solo (UFPR) e professor da Rede Pública de Ensino do Paraná. 
MENEGUZZO, I. S. Considerações acerca do atual contexto socioeconômico e educacional do Brasil...

\section{INTRODUÇÃO}

A humanidade vive um momento histórico marcado por problemas que variam desde a disseminação de doenças infectocontagiosas até a degradação ininterrupta dos recursos naturais. Os fatores geradores de tais problemas são muito variados, pois englobam problemas que vão desde aspectos relacionados à economia de uma nação até as questões éticas, morais e culturais que permeiam a sociedade. Nesse sentido, o Brasil, ainda considerado como um país emergente, não foge a essa regra.

Desde meados do século $\mathrm{XVI}$ até os dias atuais, as classes dominantes internacionais e posteriormente nacionais vêm atuando social, política e economicamente de modo significativo no Brasil, impondo dessa forma as suas vontades e aspirações.

Santos (2005b) aponta para a questão de que os laços de dependência econômica em relação aos chamados países desenvolvidos vêm aumentando a cada ano por inúmeras razões, sendo que a principal delas é o processo de globalização econômica. Como conseqüência, as desigualdades socioeconômicas no âmbito do território brasileiro vêm se intensificando.

As evidências podem ser percebidas por meio de dados periodicamente publicados, principalmente em jornais, revistas e sites oficiais de instituições governamentais, que demonstram o aumento da criminalidade e o aumento no número de pessoas situadas nos empregos informais, por exemplo.

Perante esse contexto, o presente artigo apresenta uma discussão sucinta em relação aos aspectos sociais, econômicos e educacionais do Brasil e sua repercussão no pensamento de conservação ambiental.

\section{CONSIDERAÇÕES SOBRE O CONTEXTO SOCIOECONÔMICO E EDUCACIONAL DO BRASIL}

Jaguaribe (2006) aponta para o fato de que, mais do que subdesenvolvido, o Brasil é um país socialmente desequilibrado em relação à socioeconomia, e desse desequilíbrio é que decorre seu subdesenvolvimento.

É notório que os problemas socioeconômicos do Brasil remetem ao contexto histórico de expansão marítima dos países europeus em período posterior ao século XV (PRADO JÚNIOR, 1987, p. 13). Associa-se $a$ isso o fato de que "o Brasil consistiu numa grande fazenda tropical, explorada, até fins do século XIX, pelo braço escravo e, a partir de então, por um campesinato miserável, sub-remunerado e deseducado"
(JAGUARIBE, 2006, p. 10) cujas matrizes estiveram baseadas no conservadorismo agrário (LINHARES; TEIXEIRA DA SILVA, 1999, p. 75).

Desde o período de colonização até os dias atuais, o laço de dependência econômica em relação aos países desenvolvidos vem aumentando, principalmente após a $2^{\mathrm{a}}$ Guerra Mundial, e em especial desde a década de 1960, quando mundialmente o papel das economias nacionais tem sido alterado pela divisão internacional do trabalho, cujas unidades básicas são as organizações multinacionais e transnacionais (HOBSBAWM, 1991, p. 206). Como conseqüência disso, as desigualdades socioeconômicas no âmbito do território brasileiro vêm se intensificando nas duas últimas décadas.

Segundo Hobsbawm (1991), as economias nacionais vêm sendo corroídas ou mesmo colocadas em questão pelas principais transformações no âmbito da divisão internacional do trabalho, cujas unidades básicas são organizações de diversos tamanhos, multinacionais e transnacionais, e pelo desenvolvimento correspondente dos centros internacionais e redes de transformações econômicas que estão, para fins práticos, fora do controle dos governos dos Estados.

Atualmente, o Brasil vive num contexto marcado pelo produtivismo (GONÇALVES, 2002, p. 118) e pelo consumismo, que é a característica básica da moderna sociedade capitalista (BUARQUE, 1993, p. 126). Cabe destacar que o desenvolvimento do modo de produção capitalista operou uma mudança de valores e de ideologia (VESENTINI, 1989, p. 24): a sociedade de consumo e a visão de mundo que a conforma remetem a um comprometimento do individual com a lógica de acumulação, que se concretiza por essa sociedade que, para se desenvolver, explora os recursos naturais, degradando-os e exaurindo-os. (GUIMARÃES, 2002, p. 85)

Santos (2005b) comenta que a competitividade é a responsável pelo abandono da noção e do fato da solidariedade. Disso decorrem a ampliação do desemprego, o abandono da educação e o desapreço à saúde.

Nesse sentido, Morin (1997) aponta que a única medida para manter a sociedade coesa é que haja o sentimento de comunidade e solidariedade no interior de cada pessoa pertencente à sociedade.

Conforme ressalta Galeano (1983), os povos pobres da América Latina desde sempre constituiramse em objeto de exploração em relação aos europeus. Tal situação é explicada e até justificada de diversas maneiras e com as mais variadas argumentações. As evidências indicam que os interesses dos povos ricos conjugam-se, muitas vezes, com os interesses das chamadas elites, que normalmente detêm o poder eco- 
MENEGUZZO, I. S. Considerações acerca do atual contexto socioeconômico e educacional do Brasil...

nômico e o poder político nas nações subdesenvolvidas, desencadeando, a partir dessa comunhão de objetivos, ações nos planos político e econômico que visam tão somente a preservação de privilégios, bem como a neutralização de possíveis mutações sociais, políticas ou econômicas que possam colocar em risco uma situação relativamente tranqüila de dominação.

Diante desse panorama, os agentes nacionais e internacionais da exploração reagem ampliando o seu campo de controle, que passa do plano econômico e político para o plano cultural, pois o desenvolvimento cultural leva o homem a refletir sobre os seus problemas e a elaborar soluções para os mesmos.

Na visão das classes dominantes, é necessário evitar que o homem pense ou que a juventude reflita, porque só assim é possível impedir mutações sociais. Nesse contexto, a educação é peça fundamental e os veículos de comunicação são poderosos instrumentos na formação de opinião pública. É imprescindível educar de acordo com as conveniências ou não educar e controlar os instrumentos formadores de opinião pública.

As condições básicas para a sobrevivência, como saúde, alimentação e emprego dos seres humanos, estão cada dia mais distantes de níveis satisfatórios, em termos qualitativos. Isso se deve basicamente às políticas econômicas implantadas no país, à má vontade e à perversidade de políticos, aos interesses internacionais e até mesmo ao estilo acomodado do cidadão brasileiro, pois, como afirma Prado Júnior (1987), a decisão firme de um povo é mais forte que qualquer poder governamental.

O objetivo de todos os povos do mundo, a ser seguido a qualquer custo, é o da opulência material dos países europeus ocidentais, dos Estados Unidos, do Canadá e do Japão (PENNA, 1999, p. 48). Esse fato constitui um empecilho ao desenvolvimento de uma postura reflexiva por parte da população, no que se refere ao entendimento dos acontecimentos sociais, ambientais, econômicos e políticos.

Para Soffiati (2005), a educação, em seu sentido mais amplo, enfrenta significativos problemas relacionados à qualidade e não alcançou patamares desejáveis de democratização. A título de ilustração, a informação a seguir atesta a falta de comprometimento das autoridades em relação à educação no Brasil: aproximadamente $21,3 \%$ dos 5.559 municípios brasileiros não possuem bibliotecas públicas (BERTOLETTI, 2004, p. 86).

Para Calloni (2005, p. 69), a crise da educação não está na educação: "A crise da educação é tradução imediata da crise de objetivos e da saturação do modelo capitalista."
Ressalta-se que interesses econômicos internacionais foram os responsáveis pela elaboração e vigência de leis que constituem a base legal da educação no Brasil. Lampert (2005) aponta para o fato de que nunca se deu tanta importância à educação, ao ensino eao conhecimento, porém, com exceções, percebe-se a instalação do caos nas diversas esferas e níveis de escolaridade. Aranha (1989) aponta o fato de que a educação e a escola constituem um espaço possível e importante de luta contra-hegemônica, ainda que limitado.

No âmbito da educação brasileira ${ }^{2}$, o arcabouço legal estimula, de modo mascarado, a formação de cidadãos pouco capazes em refletir sobre sua situação social, econômica e cultural e como é a qualidade do ambiente que os cerca. As médias necessárias para aprovação, os índices de reprovação e a própria qualidade no ensino público são os principais fatores deflagradores dessa formação inadequada dos estudantes.

Morin (1997) afirma que a educação acabou ensinando as pessoas a separarem e isolarem os fatos. Existe uma tendência em separar os objetos de seu contexto, ou seja, da realidade que cerca as pessoas.

\section{A QUESTÃO AMBIENTAL E A IDÉIA DE CONSERVAÇÃO AMBIENTAL}

Foram somente entre as décadas de 1960 e 1970 que se tornaram mais evidentes e generalizados os indicadores de uma crise socioambiental de amplas proporções (COSTA LIMA, 2005, p. 110). Mesmo assim, a humanidade continuou trilhando seu caminho chegando até a atualidade, quando diversos problemas afligem a mesma, de diferentes formas e intensidades.

Embora nas duas últimas décadas do século passado, registrou-se um estado de profunda crise mundial. A complexidade de tal crise afetou diversos aspectos da vida do homem, tal como a saúde, o modo de vida e a qualidade do meio ambiente. (CAPRA, 1997, p. 19) Essa crise tenha atingido um número significativo de países do mundo, inclusive o Brasil, atitudes concretas deveriam ser implementadas e estarem direcionadas para solucionar tal crise, com vistas a preservar a cidadania das pessoas.

Santos menciona (1996a) o fato de que as técnicas atualmente atreladas ao conhecimento científico contribuem de modo eficiente no que se refere à aplicabilidade do conhecimento no dia-a-dia do mundo capitalista. Dessa forma, as técnicas são empregadas no meio produtivo visando o lucro e assim acarretam mudanças no meio natural.

2 Cf., por exemplo, a Lei de Diretrizes e Bases da Educação Nacional, Lei n. 9394/99. 
MENEGUZZO, I. S. Considerações acerca do atual contexto socioeconômico e educacional do Brasil...

Casseti (1995) comenta que a sociedade constitui-se num organismo complexo cuja organização interna representa um conjunto de ligações e relações baseadas no trabalho, que é visto como mediador na relação do homem com a natureza. As formas como os homens se relacionam com ela depende da maneira como se relacionam entre si, sendo que a transformação da mesma ocorre por meio do emprego de técnicas, com a finalidade de produção.

Ressalta-se, porém que a solução dos problemas ambientais não é de natureza técnica, mas de uma opção político-cultural, pois afinal a técnica deve servir à sociedade e não esta ficar subordinada àquela. (GONÇALVES, 2002, p. 123-124)

Embora exista desde o ano de 1965 o Código Florestal Brasileiro e desde 1981 a Política Nacional do Meio Ambiente, no caso do Brasil, foi somente com o advento da promulgação da Constituição Federal, no ano de 1988, que a questão ambiental passou a ter destaque (ARAÚJO, 1999, p. 199-200). Desse período em diante, ressalta-se a $2^{\mathrm{a}}$ Conferência das Nações Unidas sobre Meio Ambiente, conhecida como ECO-92, realizada no Rio de Janeiro, na qual houve discussões entre representantes de diversos países do mundo com pessoas componentes dos diferentes segmentos da sociedade.

Gonçalves (2002) comenta que, no Brasil, foi somente na década de 1970 que o movimento ecológico emerge, estabelecendo uma série de reivindicações de caráter socioambiental.

Nesse contexto, surge uma possibilidade de minimização para os problemas socioambientais: o desenvolvimento sustentável. Com o objetivo de promover o desenvolvimento econômico, social, político, cultural e ambiental é que emerge a idéia de desenvolvimento sustentável (VARGAS, 2002, p. 212). Santos (2004) comenta que o desenvolvimento sustentável possui suas raízes na década de 1950, foi difundido em 1970 e oficializado em 1987, no documento denominado Relatório Brundtland.

Em síntese, o desenvolvimento sustentável visa promover o crescimento econômico de forma harmônica, com a utilização racional dos recursos naturais.

Ressalta-se que a idéia de conservação ambiental está intimamente atrelada à idéia de desenvolvimento sustentável, pois a palavra conservação refere-se à exploração ambiental racional.

O desenvolvimento sustentável prevê a educação ambiental como instrumento de melhoria da qualidade de vida, por meio da formação de cidadãos conscientes de sua participação local no contexto da conservação ambiental global. (HAMMES, 2004, p. 11)
Nesse sentido, cabe a cada cidadão cumprir seu papel perante os diferentes problemas de caráter socioambiental que afligem a sociedade, mas para isso os mesmos devem possuir padrões mínimos de conscientização ambiental.

Conforme Penna (1999), num mundo onde a necessidade humana de valorizar-se e ser respeitado pelos seus semelhantes manifestam-se, de forma crescente, por meio do consumismo e da compra de bens supérfluos, torna-se difícil desenvolver um pensamento crítico e reflexivo em relação à questão socioambiental nas pessoas pertencentes à elite. E talvez mais complexo ainda seja em relação às pessoas pertencentes à classe baixa, pois, como nos diz Manucci, (2004, p. 25), "é difícil falarmos de sociedade sustentável em um país onde a miséria e a fome ainda estão presentes".

O modo de produção capitalista e a visão linear dos processos socioeconômicos acabam acarretando uma alteração de valores que por sua vez repercutem de forma negativa no meio ambiente.

\section{CONSIDERAÇÕES FINAIS}

A subordinação histórica à economia internacional impelida por interesses relacionados às classes nacionais e internacionais dominantes é certamente uma das maiores responsáveis pelos problemas socioeconômicos e ambientais contemporâneos do país.

Presume-se dessa forma que os problemas de caráter socioeconômico e conseqüentemente ambientais contemporâneos que são atualmente vistos no país decorrem fundamentalmente do modo de produção capitalista atrelado à perda de poder dos governos, nas diversas esferas, sejam elas federal, estaduais ou municipais.

Perante as idéias aqui apresentadas, cabe destacar que a participação das populações da classe inferior junto aos políticos nas tomadas de decisão pode conduzir a caminhos dignos para a nação brasileira e conseqüentemente para a questão da conservação ambiental. De forma genérica, considera-se um desafio a idéia de participação das classes menos favorecidas nos processos decisórios que envolvem diversos assuntos pertinentes à sociedade em geral. Deve haver um investimento maciço de recursos financeiros no âmbito da educação.

Os cidadãos devem estar aptos a compreender a realidade que os cerca nos diferentes níveis: social, econômico, político, cultural e ambiental. Parece plausível a idéia de que se necessita sanar concomitantemente todos os problemas supracitados e desenvolver um pensamento crítico referente à conservação ambiental. 
MENEGUZZO, I. S. Considerações acerca do atual contexto socioeconômico e educacional do Brasil...

Os preceitos éticos devem estar presentes na esfera política, econômica, educacional e ambiental, pois, sem estes, de pouco valerão os esforços até então realizados no que se refere à conservação ambiental.

A visão antropocêntrica deveria ser substituída por uma visão biocêntrica, fundamentada nos aspectos ecológicos, que são de vital importância para a manutenção do equilíbrio ambiental e, conseqüentemente, base para a sustentação da vida dos seres humanos.

Nesse sentido, o conceito de desenvolvimento sustentável deve ser aplicado nos processos produtivos, divulgado e trabalhado nos diferentes segmentos da sociedade e nos diversos níveis de ensino, público e privado.

\section{AGRADECIMENTO}

Ao professor Ivan Meneguzzo, por sua grandeza de pensamento, fonte de inspiração para redigir este artigo.

\section{REFERÊNCIAS}

ARANHA, M. L. A. Filosofia da educação. São Paulo: Moderna, 1989.

ARAÚJO, L. A. Perícia ambiental em ações civis públicas. In: CUNHA, S. B.; GUERRA, A. J. T. Avaliação e perícia ambiental. Rio de Janeiro: Bertrand Brasil, 1999. p. 173-215.

BERTOLETTI, E. C. A memória da comunicação impressa brasileira e o exercício da cidadania. In: OLIVEIRA, M. J. C. Comunicação pública. Campinas: Alínea, 2004. p. 81-96.

BUARQUE, C. A desordem do progresso: o fim da era dos economistas e a construção do futuro. 4. ed. Rio de Janeiro: Paz e Terra, 1993.

CALLONI, H. A educação e seus impasses: um olhar a partir da noção de pós-modernidade. In: LAMPERT, E. Pós-modernidade e conhecimento: educação, sociedade, ambiente e comportamento humano. Porto Alegre: Sulina, 2005. p. 49-75.

CAPRA, F. O ponto de mutação: a ciência, a sociedade e a cultura emergente. São Paulo: Cultrix, 1997.

CASSETI, V. Ambiente e apropriação do relevo. 2. ed. São Paulo: Contexto, 1995.

COSTA LIMA, G. F. Crise ambiental, educação e cidadania: os desafios da sustentabilidade emancipatória. In: BIANCHINI BAETA, A. M. et al. Educação ambiental: repensando o espaço da cidadania. 3. ed. São Paulo: Cortez, 2005. p. 109-143.

GALEANO, E. As veias abertas da América Latina. 19. ed. Rio de Janeiro: Paz e Terra, 1983.
GONÇALVES, C. W. P. Os (des)caminhos do meio ambiente. São Paulo: Contexto, 2002.

GUIMARÃES, M. Sustentabilidade e educação ambiental In: CUNHA, S. B.; GUERRA, A. J. T. A questão ambiental: diferentes abordagens. Rio de Janeiro: Bertrand Brasil, 2003. p. 81-105.

HAMMES, V. S. Proposta metodológica de macroeducação. São Paulo: Globo, 2004.

HOBSBAWM, E. Nações e nacionalismo. Rio de Janeiro: Paz e Terra, 1991.

JAGUARIBE, H. Atual problema do desenvolvimento brasileiro. Revista Brasileira de Ciências Sociais, São Paulo, v. 21, n. 60 , p. 5-13, fev. 2006.

LAMPERT, E. Pós-modernidade e educação. In: LAMPERT, E. Pós-modernidade e conhecimento: educação, sociedade, ambiente e comportamento humano. Porto Alegre: Sulina, 2005. p. 11-48.

LINHARES, M. Y.; TEIXEIRA DA SILVA, F. C. Terra prometida: uma história da questão agrária no Brasil. Rio de Janeiro: Campus, 1999.

MANUCCI, M. Sociedade sustentável. In: HAMMES, V. S. Proposta metodológica de macroeducação. 2. ed. São Paulo: Globo Embrapa, 2004. p. 25-28.

MORIN, E. Complexidade e ética da solidariedade. In: CASTRO, G.; CARVALHO, E. A.; ALMEIDA, M. C. Ensaios de Complexidade. Sulina: Porto Alegre, 1997. p. 15-24.

PENNA, C. G. O estado do planeta: sociedade de consumo e degradação ambiental. Rio de Janeiro: Record, 1999.

PRADO JÚNIOR, C. História econômica do Brasil. 35. ed. São Paulo: Brasiliense, 1987.

SANTOS, M. Do meio natural ao meio técnico-científicoinformacional. In:__. A natureza do espaço: técnica e tempo, razão e emoção. São Paulo: Hucitec, 1996a. p. 186207.

SANTOS, M. Por uma outra globalização: do pensamento único à consciência universal. 12. ed. São Paulo: Record, 2005 b.

SANTOS, R. F. Planejamento ambiental: teoria e prática. São Paulo: Oficina de Textos, 2004.

SOFFIATI, A. Fundamentos filosóficos e históricos para o exercício da ecocidadania e da ecoeducação. In: BIANCHINI BAETA, A. M. et al. Educação ambiental: repensando o espaço da cidadania. 3. ed. São Paulo: Cortez, 2005. p. 23-68.

VARGAS, P. R. O insustentável discurso da sustentabilidade. In: BECKER, D. M. Desenvolvimento sustentável: necessidade ou possibilidade. 4. ed. Santa Cruz do Sul: EDUNISC, 2002. p. 212-240.

VESENTINI, J. W. Geografia, natureza e sociedade. São Paulo: Contexto, 1989. 
